$-25 \%$ and is thus clearly distinguishable from that originating from the ocean.

Figure 2 shows a seasonally adjusted record of $\delta^{13} \mathrm{C}$. Excursions towards lower values of $\delta^{13} \mathrm{C}$ (notice inverted scale) are observed in 1983-84 and 1987-88 and also $1979-80$, occurring at the same time as the anomalous increases in $\mathrm{CO}_{2}$ (Fig. 1) after an ENSO event. The anomalies are small, comparable to the analytical precision, but it seems unlikely that they are an experimental artefact, as they are found in the individual isotopic records for both Mauna Loa and the South Pole. Thus, the isotope data suggest that the positive $\mathrm{CO}_{2}$ anomalies are of biospheric origin.

Examining both the isotopic records and the records of $\mathrm{CO}_{2}$ concentration allows both the biospheric and oceanic sources to be identified: from the anomalies in $\mathrm{CO}_{2}$ concentration, the sum of biospheric and oceanic sources (or sinks) can be estimated, and anomalies in $\delta^{13} \mathrm{C}$ allow the size of the biospheric contribution alone to be estab- average of results from Mauna Loa and the South Pole ${ }^{1}$. The lished. Keeling et al. have vertical scale is inverted to facilitate comparison with Fig. 1. carried out a double deconvolution of the two records and obtained estimates for the 'anomalous' oceanic and biospheric $\mathrm{CO}_{2}$ fluxes. Both fluxes are found to be large, up to $4 \mathrm{Gt} \mathrm{C}$ per year, and are out of phase: namely, biospheric release and oceanic uptake of carbon occur during and after an ENSO event, with the biospheric flux dominating, thus causing a net release of $\mathrm{CO}_{2}$ to the atmosphere.

Is this result realistic? Qualitatively, it is certainly plausible. Ordinarily, surface waters in the equatorial Pacific Ocean have a high partial pressure of $\mathrm{CO}_{2}\left(P_{\mathrm{CO}_{2}}\right)$, with values $50-100$ p.p.m. higher than in the atmosphere. This peak in $P_{\mathrm{CO}_{2}}$ is due to the upwelling of $\mathrm{CO}_{2}$-rich water from depths of $100 \mathrm{~m}$ to a few $100 \mathrm{~m}$ and the resulting degassing from the equatorial Pacific corresponds to a source of about 1 $\mathrm{Gt} \mathrm{C}$ per year. During an El Nin̄o event, upwelling stops and therefore the $\mathrm{CO}_{2}$ outgassing ceases. Although this is directly supported only by a few $P_{\mathrm{CO}_{2}}$ measurements during the 1982 event, there is clear evidence from data on total carbon and on nutrients that $P_{\mathrm{CO}}$ must have decreased. This is confirmed by box model studies ${ }^{2,3}$ in which the physical, chemical and biological changes in the Pacific Ocean during an ENSO event are simulated. During such an event, the upwelling of water rich in $\mathrm{CO}_{2}$ and nutrients into the equatorial surface mixed layer ceases; the temperature of the surface water increases and biological activity decreases (because of reduced availability of nutrients), as does the export of carbon by sinking organic particles. These last two effects would tend to increase $P_{\mathrm{CO}_{2}}$ in the surface water,

but the first - which dominates - leads to a decrease of $P_{\mathrm{CO}_{2}}$. Although the two model studies ${ }^{2.3}$ differ in the details, both obtain the same decrease, about 0.4 p.p.m. (or $0.8 \mathrm{Gt} \mathrm{C}$ ), in atmospheric $\mathrm{CO}_{2}$ during an El Niño. The pattern of oceanic fluxes as predicted by the box models is in qualitative agreement with the pattern deduced by Keeling et al., but their estimate of the oceanic $\mathrm{CO}_{2}$ flux, up to 2 p.p.m. change within a year, is larger than can be explained by the models.

The biospheric contribution also seems plausible. During an El Niño, rainfall is in colween El Nino and the weak ing (Fig. 1). Consequently, there is apparently reduced uptake of $\mathrm{CO}_{2}$ by vegetation over large areas, so that the anomalous atmospheric $\mathrm{CO}_{2}$ increase during an EI Niño seems essentially to be due to a reduced biospheric $\mathrm{CO}_{2}$ sink.

In view of the relatively small $\mathrm{CO}_{2}$ signals involved, one may wonder whether the story is relevant to discussions on the carbon cycle - the ENSO-related anomalies can hardly lead to changes in atmospheric $\mathrm{CO}_{2}$ that would influence the greenhouse effect. The observed anomalies of 1-2 Gt C per year do, however, correspond to several per cent of the total terrestrial net primary productivity. This is a significant perturbation, particularly because it has its origin in only a restricted part of the land biota, and is important enough to be studied in more detail. As usual, what are needed are further longterm high-precision records of $\delta^{13} \mathrm{C}$ and $\mathrm{CO}_{2}$ concentration from stations near tropical ecosystems, and direct $P_{\mathrm{CO}_{2}}$ observations in the equatorial Pacific Ocean

Uirich Siegenthaler is in the Physics Institute, University of Berne, Sidlerstrasse $5, \mathrm{CH}-3012$, Berne, Switzerland. Pacific and the Western Americas (ed. Peterson, D. H.) Geophys. Monogr. 55, 165-236 (Am. Geophys. Union. Washington, D.C., 1989)

2. Volk, T. Global biogeochem. Cycles 3, 267-279 (1989).

3. Siegenthaler, U. \& Wenk, T. in Extended Abstr. 3rd Int. CO Conference Environmental Pollution Monitoring and Research Programme No. 59, 189-194 (World Meteorological Organization, Geneva 1989). during an El Niño.

1. Keeling, C. D. et al. in Aspects of Climate Variability in the

\section{Purifying earth}

LAST week Daedalus proposed a novel deep-sea mining scheme, in which two boreholes were sunk in the sea floor to such a depth that the hot pressurized water would dissolve the rock between them. Thereafter, a convective flow would be established, with cold sea water sinking down one of the holes, and emerging from the other very hot, and saturated with minerals in solution. He now plans to try the same scheme on land.

DREADCO prospectors are studying hot-spring districts in Iceland and New Zealand, and the geothermal regions of southwest England, where hot rock is very near the surface. A borehole in such a region should soon reach a depth where water would boil but for the strong hydrostatic pressure above it. The hotter and more pressurized the water, the more ferocious it becomes as a solvent. Once the hole has reached a certain critical depth, it need only be kept full of water and it will dissolve its way deeper and deeper without further drilling. Two holes a suitable distance apart will ultimately join up by sideways diffusion of the water. A self-sustaining convective flow between them could then be easily established.

This simple arrangement would be a wonderful source of geothermal heat and deep-dissolved minerals. But Daedalus also sees it as a splendid new waste-disposal and sewage-treatment plant. Sewage, possibly loaded with suspended urban waste and industrial nasties like chlorinated residues, would simply be poured into the downflow pipe. In the heated and pressurized depths, all the solids would dissolve in the water and would begin to react with it and the surrounding rocks. Some of the metals in the waste, like sodium and aluminium, would probably be trapped by ion-exchange processes; others, like iron, copper, and manganese from spent batteries, would go to stable sulphide or carbonate minerals for reclamation. The organics, from paper and plastics to food waste and sewage solids, should hydrolytically oxidize, ultimately to carbon dioxide. All the waste of civilization would be disposed of simply and with total ecological rectitude!

The final outflow, with luck, would be a sterile solution of minerals in almost pure water. Once the minerals had precipitated out and the dissolved gases had fizzed away, it might almost be fit to drink! But even Daedalus is not quite so optimistic. He would prefer to arrange the pressure-gradient in the outflow so that the exitwater partly boils on its way up. The steam, after driving turbines for power, could be condensed to pure distilled water for domestic distribution. The residual mineral-loaded stream, concentrated by its partial evaporation, could be filtered to recover its metals.

David Jones 